\title{
Effects of Selenium on Differentiation and Antioxidant Activity of Sclerotium of Penicillium thomii Q1 Strain
}

\author{
Wenjing Zhao $\mathbb{D}^{1}{ }^{1}$ Feihong Zhai, ${ }^{1}$ and Jianrong Han ${ }^{2}$ \\ ${ }^{1}$ Taiyuan Normal University, Jinzhong, China \\ ${ }^{2}$ Shanxi University, Taiyuan, China \\ Correspondence should be addressed to Wenjing Zhao; maomaozx@126.com
}

Received 27 January 2020; Revised 20 March 2020; Accepted 31 March 2020; Published 27 April 2020

Academic Editor: Yun-Peng Chao

Copyright ( 2020 Wenjing Zhao et al. This is an open access article distributed under the Creative Commons Attribution License, which permits unrestricted use, distribution, and reproduction in any medium, provided the original work is properly cited.

\begin{abstract}
Selenium is an essential trace element, which has certain antioxidant properties. $\mathrm{Na}_{2} \mathrm{SeO}_{3}$ is toxic, and its use is limited. SeMet, as an organic selenium, is less toxic than $\mathrm{Na}_{2} \mathrm{SeO}_{3}$. In this experiment, different concentrations of $\mathrm{Na}_{2} \mathrm{SeO}_{3}$ and SeMet were added to MEA and PDA media to observe the effect of selenium on the sclerotium differentiation of Q1 strain, and the contents of carotenoids, ascorbic acid, and total phenol and their reducing power, DPPH free radical scavenging ability, ferrous ion chelating ability, and superoxide anion scavenging ability were determined. Meanwhile, the orthogonal design was used to optimize the selenium enrichment culture conditions of Q1. The results showed that the addition of selenium in the PDA medium was not conducive to the differentiation of Q1 strain. The addition of inorganic and organic selenium in the MEA medium at different concentrations resulted in the accumulation of carotenoids, ascorbic acid, phenols, and selenium in the sclerotia of Q1 strain, and the contents of carotenoids, ascorbic acids, and selenium in the sclerotia of Q1 strain were increased to different degrees, but it cannot increase the content of total phenol. In addition, when the concentration of $\mathrm{Na}_{2} \mathrm{SeO}_{3}$ and SeMet in the medium was $10 \mu \mathrm{g} / \mathrm{mL}$, the reducing power of the extract was improved. The experimental results can provide a new research idea for the utilization and development of Penicillium sclerotium and selenium.
\end{abstract}

\section{Introduction}

Certain soil-borne fungi differentiate by forming compact multicellular structures called sclerotia in order to propagate asexually and survive in nature under adverse environmental conditions [1-4]. Because of the biological and agricultural significance of the sclerotiogenic fungi, considerable research efforts have been directed towards elucidating the mechanism of sclerotial biogenesis [5]. Oxidative stress is a disturbance of the cellular redox status that is often observed in stress situations. In nonstress conditions, ROS and other oxidants are balanced against the antioxidative defense system, which is composed of enzymes as well as metabolites [6]. All subcellular compartments contain specific antioxidative enzymes or metabolites that are coordinated and controlled by underlying regulatory mechanisms. Some nonenzymatic molecules can be extracted from sclerotia. These nonenzymatic molecules like ascorbic acid influence multiple signaling pathways [7] and can scavenge free radicals as natural antioxidants. Due to many synthetic antioxidants such as butylated hydroxyanisole, butylated hydroxytoluene, t-butylhydroquinone, and propyl gallate, there exist potential health hazards in many fields [8]. Currently, there is a great deal of interest in the study of natural compounds with free radical scavenging capacity. Researchers are continuously seeking those natural antioxidants that will sufficiently protect fats and oils from oxidation. Recent research has focused on antioxidant compounds derived from leaves and fruit of olive trees, numerous fruits and vegetables, and aromatic plants and spices [9]. But the antioxidant activity of fungi which produced sclerotia (mainly microsclerotia) has not been reported.

Selenium has many important biological functions: (1) antioxidant function [10]; (2) enhancing immune function. Selenium has significant effects on specific immunity (including cellular immunity and humoral immunity) and nonspecific immunity in the immune system [10-11]; (3) the function of antagonizing metal toxicity; (4) the function 
of promoting growth; and (5) other functions. Selenium also has important functions such as improving animal reproductive capacity, preventing cancer, and protecting the heart [11].

A strain of Penicillium thomii Q1 was isolated from a soil sample and was able to form abundant orange, sand-shaped sclerotia in which carotenoids accumulated. We had studied the culture condition influencing sclerotial growth and carotenoid production of Q1 strain [12].

In the body, selenium is an essential trace element, which has a certain degree of oxidation resistance, and it will have a synergistic effect with VE and other antioxidants [11]. Carotenoid and ascorbic acid can be accumulated in the sclerotia of Q1 strain, and they have certain antioxidant activity [13-14].

In this experiment, different concentrations of sodium selenite $\left(\mathrm{Na}_{2} \mathrm{SeO}_{3}\right)$ and selenomethyline (SeMet) were added to MEA and PDA media to observe the effect of selenium on the sclerotium differentiation of Q1 strain, and the contents of carotenoids, ascorbic acid, and total phenol and their reducing power, DPPH free radical scavenging ability, ferrous ion chelating ability, and superoxide anion scavenging ability were determined.

\section{Experimental}

2.1. Strain. The strain of Penicillium sp. Q1 was isolated from the soil of Wutai Mountain in Shanxi Province and preserved in CA medium. Q1 strain was identified as Penicillium thomii (KC966729) by rDNA ITS sequence analysis [15].

\subsection{Media. The media are the following.}

$M E A$ : malt extract $20 \mathrm{~g}$, peptone $1.0 \mathrm{~g}$, glucose $20 \mathrm{~g}$, agar $20 \mathrm{~g}$, and distilled water $1000 \mathrm{~mL}$.

Potato glucose agar medium (PDA): $1000 \mathrm{~mL} \mathrm{20 \%} \mathrm{potato}$ juice, $20 \mathrm{~g}$ glucose, $18 \mathrm{~g}$ agar. Weigh $200 \mathrm{~g}$ potatoes, add $1000 \mathrm{~mL}$ water, boil for 20 minutes, and filter. Add enough water to $1000 \mathrm{~mL}$ in the filtrate, and the $20 \%$ potato juice will be prepared.

2.3. Growth Conditions. $\mathrm{Na}_{2} \mathrm{SeO}_{3}$ and SeMet were added to PDA and MEA media, respectively. The concentrations of $\mathrm{Na}_{2} \mathrm{SeO}_{3}$ were $3 \mu \mathrm{g} / \mathrm{mL}, 6 \mu \mathrm{g} / \mathrm{mL}$, and $10 \mu \mathrm{g} / \mathrm{mL}$, respectively. The concentrations of SeMet were $5 \mu \mathrm{g} / \mathrm{mL}, 10 \mu \mathrm{g} / \mathrm{mL}$, and $20 \mu \mathrm{g} / \mathrm{mL}$. The media without supplementation of $\mathrm{Na}_{2} \mathrm{SeO}_{3}$ and SeMet served as the control. Using three-point inoculations, three grains of sclerotia of PT95 and Q1 strain were inoculated at a $9 \mathrm{~cm}$ Petri dish containing $25 \mathrm{~mL}$ of media. Plates were incubated in the dark at $25^{\circ} \mathrm{C}$ for 25 days.

2.4. Observation on the Growth and Development of Sclerotia. In the process of culture, observe the strain every day and record the time when the exudate and the sclerotia mature. Finally, take photos under natural light with a Nikon D90 digital camera.

2.5. Sclerotial Biomass, Carotenoid Extraction, and Determination. The sclerotia on the agar surfaces in Petri plates were separated and washed thoroughly with distilled water and dried at $50^{\circ} \mathrm{C}$ at constant weight to determine sclerotial biomass.
The extraction and determination of pigments were performed as a modified procedure described by Li et al. [14].

2.6. Determination of Ascorbic Acid in Sclerotia [16-17]. Add a little $2 \%$ oxalic acid to grind $0.4 \mathrm{~g}$ of sclerotium sample, mix with $2.6 \mathrm{~mL}$ of $0.03 \% \mathrm{MPA}$ ice bath, centrifugate at $25000 \mathrm{r} / \mathrm{min}$ for $15 \mathrm{~min}$, take the supernatant, add a little $5 \%$ trichloroacetic acid (TCA) solution, cool it in ice bath for $10 \mathrm{~min}$, centrifugate at $150000 \mathrm{r} / \mathrm{min}$ for $5 \mathrm{~min}$, discard precipitated protein, and keep supernatant in refrigerator at $-80^{\circ} \mathrm{C}$ for one week.

Divide the supernatant into two parts $(0.25 \mathrm{~mL}$ each $)$, add $0.05 \mathrm{~mL}$ reagent $A$ to one part, and add $0.05 \mathrm{~mL}$ reagent $B$ to the other part. Use $0.25 \mathrm{~mL} 0.03 \%$ metaphosphoric acid (MPA) (5\% TCA as solvent) as blank, keep the mixture and blank at $37^{\circ} \mathrm{C}$ for $3 \mathrm{~h}$, take an ice bath slowly, add $0.375 \mathrm{~mL}$ $75 \% \mathrm{H}_{2} \mathrm{SO}_{4}$ of ice, place at room temperature for $30 \mathrm{~min}$, make the color change, and compare the color at $520 \mathrm{~nm}$.

\subsection{Determination of Oxidation Resistance}

2.7.1. Extraction of Antioxidants from Sclerotia. Accurately weigh $1 \mathrm{~g}$ of dry sclerotia; add $20 \mathrm{~mL}$ of $80 \%$ ethanol, respectively; extract it from a shaker at $50^{\circ} \mathrm{C} 150 \mathrm{r} / \mathrm{min}$ for $24 \mathrm{~h}$; filter the filter paper and retain the filtrate; then reextract the filter residue with $20 \mathrm{~mL}$ of $80 \%$ ethanol; combine the filtrate twice; dilute it with $80 \%$ ethanol to $100 \mathrm{~mL}$ as the mother liquor; and dry and weigh the filter residue.

2.7.2. Determination of Total Phenolic Content. The total phenolic content of the sample was determined by Folin cioncalteu colorimetry [18]. Add distilled water $(2.8 \mathrm{~mL})$ and Folin cioncalteu reagent $(0.2 \mathrm{~mL})$ into the sclerotium extract diluent $(0.4 \mathrm{~mL})$ or gallic acid (standard phenolic compound) diluent, mix them evenly, let them stand for 6-8 min, then add saturated $\mathrm{Na}_{2} \mathrm{CO}_{3}$ solution $(0.6 \mathrm{~mL})$, let them stand in the dark for $120 \mathrm{~min}$ at room temperature, and measure their OD value at $760 \mathrm{~nm}$. The standard curve was drawn with $0.02 \mathrm{mg} / \mathrm{mL}, 0.04 \mathrm{mg} / \mathrm{mL}, 0.06 \mathrm{mg} / \mathrm{mL}$, $0.08 \mathrm{mg} / \mathrm{mL}$, and $0.10 \mathrm{mg} / \mathrm{mL}$ gallic acid diluent. The total phenolic content of different extracts is expressed as gallic acid equivalent.

2.7.3. Reducing Power Assay. The reduction force of the sample was determined by the potassium ferricyanide reduction method [19].

Mix $1.0 \mathrm{~mL}$ of sample diluent of different concentrations

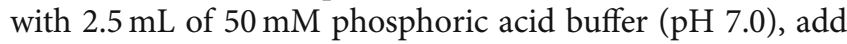
$2.5 \mathrm{~mL}$ of potassium ferricyanide solution $(1 \%)$, shake the mixture well, keep the mixture at $50^{\circ} \mathrm{C}$ for $20 \mathrm{~min}$, then cool it quickly, add $2.5 \mathrm{~mL}$ of TCA solution (10\%) and centrifugate it for $10 \mathrm{~min}$, take $1.25 \mathrm{~mL}$ of the supernatant, mix it with $1.25 \mathrm{~mL}$ of distilled water and $0.25 \mathrm{~mL}$ of $\mathrm{FeCl}_{2}$ solution $(0.1 \%)$, and measure it at $700 \mathrm{~nm}$ absorbance.

The $\mathrm{EC}_{50}$ value of the sample is calculated according to the sample curve at $700 \mathrm{~nm}$, and butylated hydroxytoluene (BHT) is used as the standard.

2.7.4. DPPH Free Radical Scavenging Activity. Scavenging activity on 1,1-diphenyl-2-picrylhydrazyl (DPPH) free 
TABLE 1: Effect of selenium on the differentiation of Q1 strain.

\begin{tabular}{lccc}
\hline Culture conditions & Time of exudate initiation (days) & Time of sclerotial initiation (days) & Time of sclerotial maturation (days) \\
\hline MEA & $5^{\mathrm{Aa}}$ & $6^{\mathrm{A}}$ & $13^{\mathrm{A}}$ \\
$\mathrm{MEA}+\mathrm{Na}_{2} \mathrm{SeO}_{3} 3 \mu \mathrm{g} / \mathrm{mL}$ & $6^{\mathrm{B}}$ & $9^{\mathrm{B}}$ & $17^{\mathrm{B}}$ \\
$\mathrm{MEA}+\mathrm{Na}_{2} \mathrm{SeO}_{3} 6 \mu \mathrm{g} / \mathrm{mL}$ & $6^{\mathrm{B}}$ & $9^{\mathrm{B}}$ & $17^{\mathrm{B}}$ \\
$\mathrm{MEA}+\mathrm{Na}_{2} \mathrm{SeO}_{3} 10 \mu \mathrm{g} / \mathrm{mL}$ & $7^{\mathrm{C}}$ & $10^{\mathrm{C}}$ & $18^{\mathrm{C}}$ \\
$\mathrm{MEA}+\mathrm{SeMet} 5 \mu \mathrm{g} / \mathrm{mL}$ & $6^{\mathrm{b}}$ & $10^{\mathrm{B}}$ & $19^{\mathrm{B}}$ \\
$\mathrm{MEA}+\mathrm{SeMet} 10 \mu \mathrm{g} / \mathrm{mL}$ & $8^{\mathrm{C}}$ & $10^{\mathrm{B}}$ & $20^{\mathrm{C}}$ \\
$\mathrm{MEA}+\mathrm{SeMet} 20 \mu \mathrm{g} / \mathrm{mL}$ & $8^{\mathrm{C}}$ & $10^{\mathrm{B}}$ & $20^{\mathrm{C}}$ \\
\hline
\end{tabular}

${ }^{\text {a }}$ Superscript letters within a column indicate that values followed by the same letter did not differ significantly $(P<0.01)$ in Duncan's multiple range test.

radical was assessed according to the method reported earlier with a slight modification [20]. Briefly, $0.2 \mathrm{~mL}$ of extracts was mixed with $0.8 \mathrm{~mL}$ of $80 \%$ ethanol. And then, $3 \mathrm{~mL}$ of DPPH solution was added. The mixture was shaken well and incubated at room temperature for $30 \mathrm{~min}$, and the absorbance was measured at $517 \mathrm{~nm}$ in a spectrophotometer; $\mathrm{EC}_{50}$ value $(\mathrm{mg} / \mathrm{mL})$ is the effective concentration at which DPPH radicals were scavenged by $50 \%$ and was obtained by interpolation from linear regression analysis. BHT was used as the standard. The experiment was performed in triplicate and averaged.

2.7.5. Determination of Chelating Ability of Ferrous Ion. The determination of the chelating ability of ferrous ions in the samples was evaluated according to the slightly modified literature [21] previously reported. Mix $1.6 \mathrm{~mL}$ of sample diluent of different concentrations with $1.6 \mathrm{~mL}$ of distilled water, add $0.4 \mathrm{~mL}$ of $\mathrm{FeCl}_{2}$ solution $(0.5 \mathrm{~mm})$, shake it well, then add $0.4 \mathrm{~mL}$ of FerroZine solution $(0.5 \mathrm{~mm})$, shake it vigorously for $1 \mathrm{~min}$, place it at room temperature for $20 \mathrm{~min}$, and measure its absorbance at $562 \mathrm{~nm}$. The absorbance was measured in solvent instead of sample:

$$
\text { Ferrous ion chelating capacity }(\%)=\times 100 \% \text {. }
$$

The $\mathrm{EC}_{50}$ value of the sample is calculated according to the sample curve at $562 \mathrm{~nm}$, and ethylene diamine tetraacetic acid (EDTA) is used as the standard.

\subsection{Determination of Selenium Content [22]}

2.8.1. Standard Curve Drawing. Take $1.0 \mathrm{~mL}-5.0 \mathrm{~mL}$ of selenium standard solution $(5 \mu \mathrm{g} / \mathrm{mL})$, respectively, and put it into the separating funnel, add $3 \mathrm{~mL}$ of o-phenylenediamine solution $(0.1 \%)$ and fill it with distilled water to about $50 \mathrm{~mL}$, mix it evenly, adjust the $\mathrm{pH}$ to 2.0 with formic acid $(80 \%)$ and concentrated ammonia water, place the mixture in the dark at room temperature for $60 \mathrm{~min}$, extract the mixture with $10 \mathrm{~mL}$ of toluene by shaking for $3 \mathrm{~min}$, and then leave it for $8 \mathrm{~min}$, discard the water layer, and turn the remaining solution transfer to a $50 \mathrm{~mL}$ volumetric flask and fix the volume with toluene, and compare the color at $335 \mathrm{~nm}$.

2.8.2. Determination of Selenium in Sclerotia. Accurately weigh $2 \mathrm{~g}$ of sclerotium, add $30 \mathrm{~mL}$ of mixed acid $\left(V_{\mathrm{HNO}_{3}}: V_{\mathrm{H}_{2} \mathrm{SO}_{4}}=4: 1\right)$, cover the top plate, and digest it in the dark for $24 \mathrm{~h}$. Heat and digest the solution after cold digestion for clarification, transfer it to a $50 \mathrm{~mL}$ volumetric flask after cooling, and fix the volume with water. Take $40 \mathrm{~mL}$ of the test solution and put it into the separating funnel, and the rest treatment is the same as above [23]:

$$
\text { Content of selenium }(\mu g / g)=\frac{C V}{W N} \text {, }
$$

where $C$ is the standard concentration of selenium obtained from the standard curve $(\mu \mathrm{g} / \mathrm{mL}), V$ is the sample volume from toluene extraction $(\mathrm{mL}), W$ is the sample weight $(\mathrm{g})$, and $N$ is the volume fraction of the sample used for determination after total constant volume.

2.9. Statistical Analysis. In the experiment, there are three repetitions, and the experimental results are expressed as the mean \pm standard deviation. At the same time, the Duncan multiple comparison method [24] is used to compare the two averages.

\section{Results}

3.1. Effect of Selenium on the Differentiation of Q1. Adding $\mathrm{Na}_{2} \mathrm{SeO}_{3}$ and SeMet of different concentrations to PDA and MEA media, the results showed that there was almost no sclerotium formation on the surface of PDA medium, which indicated that PDA medium was not conducive to the differentiation of Q1 sclerotia after adding selenium. Compared with PDA medium, MEA medium supplemented with selenium was more conducive to the differentiation of Q1sclerotia.

It can be seen from Table 1 that when $\mathrm{Na}_{2} \mathrm{SeO}_{3}$ is added to the MEA medium, with the increase of $\mathrm{Na}_{2} \mathrm{SeO}_{3}$ concentration, the emergence time of exudate of Q1 strain is delayed by 1-2 days, the emergence time of sclerotia is delayed by 3-4 days, and the maturation time of sclerotia is delayed by 4-5 days. When SeMet was added to the MEA medium, with the increase of SeMet concentration, the emergence time of exudate of Q1 strain was delayed by 1-3 days, the emergence time of sclerotia was delayed by 4 days, and the maturation time of sclerotia was delayed by 6-7 days.

3.2. Effect of Selenium on the Biomass of Q1. Table 2 lists the sclerotium biomass of Q1 strain under different seleniumenriched culture conditions. It can be seen from the table that with the increase of selenium concentration, the sclerotium biomass of Q1 strain decreased correspondingly. 
TABLE 2: Effect of selenium on the sclerotium biomass of Q1 strain.

\begin{tabular}{lc}
\hline Culture conditions & Sclerotium biomass (mg/plate) \\
\hline MEA & $0.23 \pm 0.02^{\mathrm{C}}$ \\
$\mathrm{Na}_{2} \mathrm{SeO}_{3} 3 \mu \mathrm{g} / \mathrm{mL}$ & $0.15 \pm 0.01^{\mathrm{B}}$ \\
$\mathrm{Na}_{2} \mathrm{SeO}_{3} 6 \mu \mathrm{g} / \mathrm{mL}$ & $0.11 \pm 0.03^{\mathrm{B}}$ \\
$\mathrm{Na}_{2} \mathrm{SeO}_{3} 10 \mu \mathrm{g} / \mathrm{mL}$ & $0.09 \pm 0.01^{\mathrm{A}}$ \\
$\mathrm{SeMet} 5 \mu \mathrm{g} / \mathrm{mL}$ & $0.19 \pm 0.04^{\mathrm{B}}$ \\
SeMet $10 \mu \mathrm{g} / \mathrm{mL}$ & $0.17 \pm 0.01^{\mathrm{B}}$ \\
SeMet $20 \mu \mathrm{g} / \mathrm{mL}$ & $0.13 \pm 0.02^{\mathrm{A}}$ \\
\hline
\end{tabular}

Superscript letters within a column indicate that values followed by the same letter did not differ significantly $(P<0.01)$ in Duncan's multiple range test.

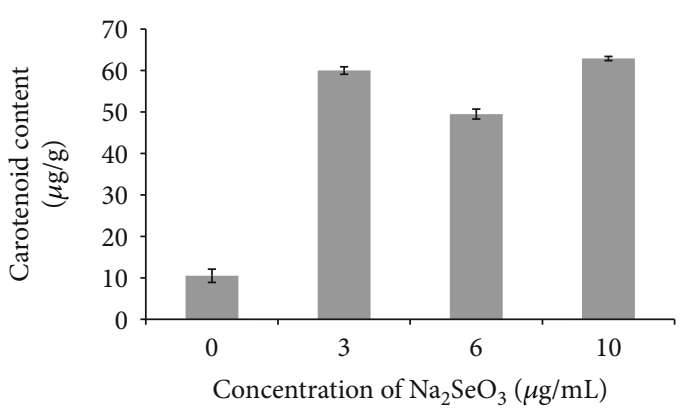

Figure 1: Effect of $\mathrm{Na}_{2} \mathrm{SeO}_{3}$ on carotenoid content in sclerotia of Q1 strain.

On the medium supplemented with $\mathrm{Na}_{2} \mathrm{SeO}_{3}$, there was a significant negative correlation between the sclerotium biomass of Q1 strain and selenium concentration $\left(R_{\mathrm{Q} 1}=-0.939\right)$. When the concentration of $\mathrm{Na}_{2} \mathrm{SeO}_{3}$ in the medium was $10 \mu \mathrm{g} / \mathrm{mL}$, the sclerotium biomass of Q1 strain was the lowest, which was $0.09 \mathrm{~g} /$ plate, 0.39 times the control.

In addition to SeMet, there was a significant negative correlation between the sclerotium biomass of Q1 strain and selenium concentration $\left(R_{\mathrm{Q} 1}=-0.985\right)$. When the SeMet concentration in the medium was $20 \mu \mathrm{g} / \mathrm{mL}$, the sclerotium biomass of Q1 strain was the smallest, which is $0.13 \mathrm{~g} / \mathrm{plate}$, 0.57 times the control.

\subsection{Effect of Selenium on Carotenoid Content in Sclerotia of} Q1 Strain. Figures 1 and 2 show the carotenoid content in the sclerotia of Q1 strain under different selenium-enriched culture conditions. It can be seen from the figure that the carotenoid content of the sclerotia of Q1 strain in different selenium-enriched culture conditions is significantly different from that in the control group $(P<0.05)$.

In the MEA medium supplemented with $\mathrm{Na}_{2} \mathrm{SeO}_{3}$, the content of carotenoids in the sclerotia of Q1 strain was positively correlated with the concentration of selenium $(R=0.752)$. When the concentration of $\mathrm{Na}_{2} \mathrm{SeO}_{3}$ in the medium was $10 \mu \mathrm{g} / \mathrm{mL}$, the content of carotenoids reached the maximum $(62.9 \mu \mathrm{g} / \mathrm{g})$, which was 5.57 times the control.

In the MEA medium supplemented with SeMet, the content of carotenoids in the sclerotia of Q1 strain was positively correlated with selenium concentration $(R=0.689)$.

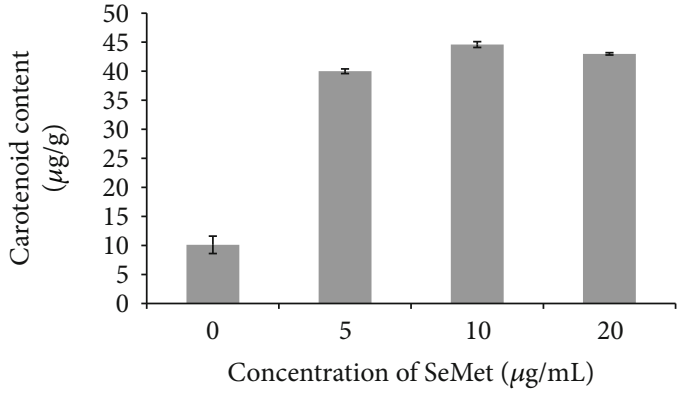

FIgURE 2: Effect of SeMet on carotenoid content in sclerotia of Q1 strain.

When the concentration of SeMet in the medium was $10 \mu \mathrm{g} / \mathrm{mL}$, the content of carotenoids reached the maximum $(44.6 \mu \mathrm{g} / \mathrm{g})$, which was 3.95 times the control.

3.4. Effect of Selenium on Ascorbic Acid Content in Sclerotia of Q1 Strain. Table 3 showed the effect of selenium on ascorbic acid content in sclerotia of Penicillium thomii Q1. It can be seen from the table that the AsA content of sclerotia grown in selenium-rich medium is higher than that of dehydroascorbic acid (DHA).

In the MEA medium, there was a positive correlation between the content of AsA and DHA in the sclerotia of Q1 strain and the concentration of $\mathrm{Na}_{2} \mathrm{SeO}_{3}\left(R_{\mathrm{AsA}}=0.683\right.$, $\left.R_{\mathrm{DHA}}=0.837\right)$ and a positive correlation between AsA/DHA and $\mathrm{Na}_{2} \mathrm{SeO}_{3}(R=0.408)$. There was a negative correlation between AsA content and SeMet concentration $\left(R_{\mathrm{AsA}}=-0.450\right)$, a positive correlation between DHA content and SeMet concentration $\left(R_{\mathrm{DHA}}=0.750\right)$, and a weak negative correlation between AsA/DHA and SeMet $(R=-0.154)$.

In the MEA medium, there was a positive correlation between AsA content and $\mathrm{Na}_{2} \mathrm{SeO}_{3}$ concentration $\left(R_{\mathrm{AsA}}=0.683\right)$, a significant negative correlation between DHA content and $\mathrm{Na}_{2} \mathrm{SeO}_{3}$ concentration $\left(R_{\mathrm{DHA}}=-0.999\right)$, and a positive correlation between AsA/DHA and $\mathrm{Na}_{2} \mathrm{SeO}_{3}$ $(R=0.790)$. There was a weak positive correlation between AsA content and SeMet concentration $\left(R_{\mathrm{AsA}}=0.194\right)$, a certain positive correlation between DHA content and SeMet concentration $\left(R_{\mathrm{DHA}}=0.365\right)$, and a weak positive correlation between AsA/DHA and SeMet $(R=0.033)$.

Compared with the control, Se-enriched culture can increase the content of AsA and DHA and AsA/DHA in the sclerotia of Q1strain. The content of AsA in sclerotia was higher than that of DHA in the same seleniumenriched culture condition.

3.5. Effect of Selenium on the Total Phenolic Content in the Sclerotia of Q1 Strain. Figure 3 shows the effect of exogenous $\mathrm{Na}_{2} \mathrm{SeO}_{3}$ added to MEA medium on the total phenolic content in the sclerotia of Penicillium thomii Q1.

In the MEA medium, there was a significant negative correlation $(R=-0.908)$ between the total phenolic content of the extract and the concentration of exogenous $\mathrm{Na}_{2} \mathrm{SeO}_{3}$. The total phenolic content of the control was the highest, reaching $15.15 \mathrm{mg} / \mathrm{g}$. Under the different culture conditions, the total phenolic content of the sclerotia was 
TABLE 3: Effect of selenium on ascorbic acid content in sclerotia of Q1 strain.

\begin{tabular}{lccc}
\hline Culture conditions & AsA content $(\mu \mathrm{g} / \mathrm{g})$ & DHA content $(\mu \mathrm{g} / \mathrm{g})$ & AsA/DHA \\
\hline MEA & $1.90 \pm 0.26^{\mathrm{A}}$ & $3.13 \pm 0.32^{\mathrm{DC}}$ & $0.61^{\mathrm{A}}$ \\
$\mathrm{Na}_{2} \mathrm{SeO}_{3} 3 \mu \mathrm{g} / \mathrm{mL}$ & $4.88 \pm 0.62^{\mathrm{C}}$ & $2.98 \pm 0.31^{\mathrm{C}}$ & $1.64^{\mathrm{B}}$ \\
$\mathrm{Na}_{2} \mathrm{SeO}_{3} 6 \mu \mathrm{g} / \mathrm{mL}$ & $4.75 \pm 0.27^{\mathrm{C}}$ & $2.82 \pm 0.16^{\mathrm{B}}$ & $1.69^{\mathrm{BC}}$ \\
$\mathrm{Na}_{2} \mathrm{SeO}_{3} 10 \mu \mathrm{g} / \mathrm{mL}$ & $4.59 \pm 0.34^{\mathrm{B}}$ & $2.64 \pm 0.18^{\mathrm{A}}$ & $1.74^{\mathrm{D}}$ \\
$\mathrm{SeMet} 5 \mu \mathrm{g} / \mathrm{mL}$ & $5.14 \pm 0.66^{\mathrm{D}}$ & $2.53 \pm 0.43^{\mathrm{A}}$ & $2.04^{\mathrm{D}}$ \\
SeMet $10 \mu \mathrm{g} / \mathrm{mL}$ & $4.08 \pm 0.14^{\mathrm{C}}$ & $3.05 \pm 0.13^{\mathrm{B}}$ & $1.34^{\mathrm{C}}$ \\
SeMet $20 \mu \mathrm{g} / \mathrm{mL}$ & $3.34 \pm 0.68^{\mathrm{B}}$ & $3.19 \pm 0.37^{\mathrm{C}}$ & $1.05^{\mathrm{B}}$ \\
\hline
\end{tabular}

Superscript letters within a column indicate that values followed by the same letter did not differ significantly $(P<0.01)$ in Duncan's multiple range test.

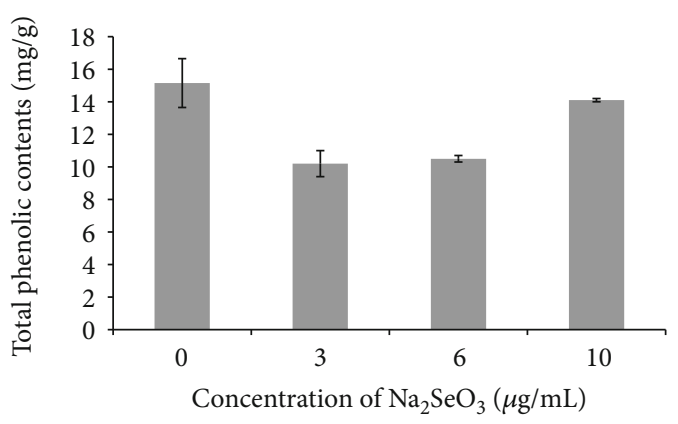

Figure 3: Effect of $\mathrm{Na}_{2} \mathrm{SeO}_{3}$ on the total phenolic content in the sclerotia of Q1 strain.

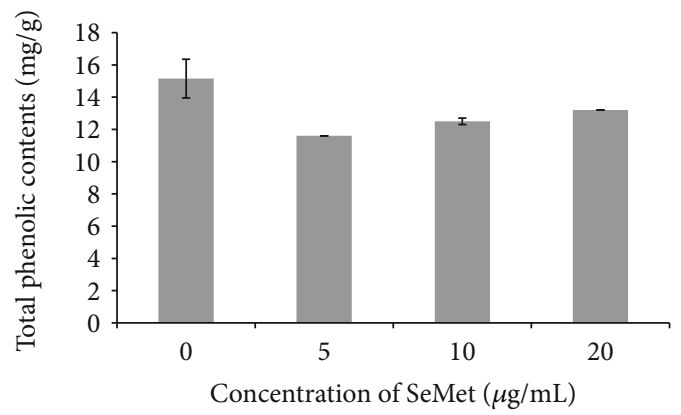

Figure 4: Effect of SeMet on the total phenolic content in the sclerotia of Q1 strain.

\section{$\mathrm{MEA}+\mathrm{Na}_{2} \mathrm{SeO}_{3} \quad 10 \mu \mathrm{g} / \mathrm{mL}>\mathrm{MEA}+\mathrm{Na}_{2} \mathrm{SeO}_{3} \quad 6 \mu \mathrm{g} / \mathrm{mL}>\mathrm{MEA}$} $+\mathrm{Na}_{2} \mathrm{SeO}_{3} 3 \mu \mathrm{g} / \mathrm{mL}$.

Figure 4 showed the effect of adding SeMet to the MEA medium on the total phenolic content in the sclerotia of Penicillium thomii Q1.

In the MEA medium, there was a significant negative correlation $(R=-0.984)$ between the total phenolic content in the sclerotium extract of Q1 strain and the concentration of exogenous SeMet. The total phenolic content in the control was the highest $(15.15 \mathrm{mg} / \mathrm{g})$, and that in $\mathrm{MEA}+\mathrm{Na}_{2} \mathrm{SeO}_{3} 20 \mu \mathrm{g} / \mathrm{mL}>\mathrm{MEA}+\mathrm{Na}_{2} \mathrm{SeO}_{3}$ $10 \mu \mathrm{g} / \mathrm{mL}>\mathrm{MEA}+\mathrm{Na}_{2} \mathrm{SeO}_{3} 5 \mu \mathrm{g} / \mathrm{mL}$.

In conclusion, the addition of $\mathrm{Na}_{2} \mathrm{SeO}_{3}$ and SeMet in the MEA medium was not conducive to the increase of total phenolic content in the sclerotia of Q1 strain.
TABLE 4: Effect of selenium reduction ability on the of Q1 strain.

\begin{tabular}{lc}
\hline Culture conditions & $\mathrm{EC}_{50}(\mathrm{mg} / \mathrm{mL})$ \\
\hline $\mathrm{MEA}$ & $1.49 \pm 0.13^{\mathrm{C}}$ \\
$\mathrm{Na}_{2} \mathrm{SeO}_{3} 3 \mu \mathrm{g} / \mathrm{mL}$ & $0.88 \pm 0.05^{\mathrm{AB}}$ \\
$\mathrm{Na}_{2} \mathrm{SeO}_{3} 6 \mu \mathrm{g} / \mathrm{mL}$ & $0.92 \pm 0.03^{\mathrm{B}}$ \\
$\mathrm{Na}_{2} \mathrm{SeO}_{3} 10 \mu \mathrm{g} / \mathrm{mL}$ & $0.82 \pm 0.02^{\mathrm{A}}$ \\
$\mathrm{SeMet} 5 \mu \mathrm{g} / \mathrm{mL}$ & $1.01 \pm 0.08^{\mathrm{A}}$ \\
SeMet $10 \mu \mathrm{g} / \mathrm{mL}$ & $1.00 \pm 0.06^{\mathrm{A}}$ \\
SeMet $20 \mu \mathrm{g} / \mathrm{mL}$ & $1.05 \pm 0.06^{\mathrm{AB}}$ \\
\hline
\end{tabular}

Superscript letters within a column indicate that values followed by the same letter did not differ significantly $(P<0.01)$ in Duncan's multiple range test.

TABLE 5: Effect of selenium on DPPH radical scavenging ability of Q1 strain.

\begin{tabular}{lc}
\hline Culture conditions & $\mathrm{EC}_{50}(\mathrm{mg} / \mathrm{mL})$ \\
\hline $\mathrm{MEA}$ & $0.47 \pm 0.09^{\mathrm{A}}$ \\
$\mathrm{Na}_{2} \mathrm{SeO}_{3} 3 \mu \mathrm{g} / \mathrm{mL}$ & $0.59 \pm 0.12^{\mathrm{B}}$ \\
$\mathrm{Na}_{2} \mathrm{SeO}_{3} 6 \mu \mathrm{g} / \mathrm{mL}$ & $0.64 \pm 0.12^{\mathrm{C}}$ \\
$\mathrm{Na}_{2} \mathrm{SeO}_{3} 10 \mu \mathrm{g} / \mathrm{mL}$ & $0.41 \pm 0.02^{\mathrm{A}}$ \\
$\mathrm{SeMet} 5 \mu \mathrm{g} / \mathrm{mL}$ & $0.86 \pm 0.13^{\mathrm{C}}$ \\
SeMet $10 \mu \mathrm{g} / \mathrm{mL}$ & $0.88 \pm 0.08^{\mathrm{C}}$ \\
SeMet $20 \mu \mathrm{g} / \mathrm{mL}$ & $0.66 \pm 0.02^{\mathrm{B}}$ \\
\hline
\end{tabular}

Superscript letters within a column indicate that values followed by the same letter did not differ significantly $(P<0.01)$ in Duncan's multiple range test.

3.6. Effect of Selenium on the Reduction Ability of Q1 Strain. Table 4 showed the effect of selenium-enriched culture conditions on the reduction ability of sclerotia of Penicillium thomii Q1. It can be seen from Table 5 that in the MEA medium, there is a certain negative correlation between $\mathrm{EC}_{50}$ value of reduction ability of sclerotium extract of Q1 strain and the concentration of exogenous $\mathrm{Na}_{2} \mathrm{SeO}_{3}$ $\left(R_{\mathrm{PT} 95}=-0.793\right)$. The reduction ability under different culture conditions is $\mathrm{MEA}+\mathrm{Na}_{2} \mathrm{SeO}_{3} 10 \mu \mathrm{g} / \mathrm{mL}>\mathrm{MEA}+\mathrm{Na}_{2} \mathrm{SeO}_{3}$ $3 \mu \mathrm{g} / \mathrm{mL}>\mathrm{MEA}+\mathrm{Na}_{2} \mathrm{SeO}_{3} 6 \mu \mathrm{g} / \mathrm{mL}$.

In the MEA medium, there was a negative correlation between $\mathrm{EC}_{50}$ value of the reduction ability of the extract of Q1 strain and the concentration of SeMet $(R=-0.622)$. The reduction ability under different culture conditions 
TABLE 6: Effect of selenium on the chelating ability of ferrous ions in the sclerotia of Q1 strain.

\begin{tabular}{lc}
\hline Culture conditions & $\mathrm{EC}_{50}(\mathrm{mg} / \mathrm{mL})$ \\
\hline $\mathrm{MEA}$ & $0.41 \pm 0.11^{\mathrm{A}}$ \\
$\mathrm{Na}_{2} \mathrm{SeO}_{3} 3 \mu \mathrm{g} / \mathrm{mL}$ & $1.23 \pm 0.24^{\mathrm{B}}$ \\
$\mathrm{Na}_{2} \mathrm{SeO}_{3} 6 \mu \mathrm{g} / \mathrm{mL}$ & $1.25 \pm 0.18^{\mathrm{B}}$ \\
$\mathrm{Na}_{2} \mathrm{SeO}_{3} 10 \mu \mathrm{g} / \mathrm{mL}$ & $2.67 \pm 0.23^{\mathrm{C}}$ \\
$\mathrm{SeMet} 5 \mu \mathrm{g} / \mathrm{mL}$ & $0.94 \pm 0.13^{\mathrm{B}}$ \\
SeMet $10 \mu \mathrm{g} / \mathrm{mL}$ & $1.15 \pm 0.09^{\mathrm{C}}$ \\
SeMet $20 \mu \mathrm{g} / \mathrm{mL}$ & $2.65 \pm 0.14^{\mathrm{D}}$ \\
\hline
\end{tabular}

Superscript letters within a column indicate that values followed by the same letter did not differ significantly $(P<0.01)$ in Duncan's multiple range test.

was $\mathrm{MEA}+\mathrm{SeMet} 10 \mu \mathrm{g} / \mathrm{mL}>\mathrm{MEA}+$ SeMet $5 \mu \mathrm{g} / \mathrm{mL}>$ MEA + SeMet $20 \mu \mathrm{g} / \mathrm{mL}$.

In conclusion, when the MEA medium contains high concentration of exogenous $\mathrm{Na}_{2} \mathrm{SeO}_{3}(10 \mu \mathrm{g} / \mathrm{mL})$ and exogenous SeMet $(20 \mu \mathrm{g} / \mathrm{mL})$, it is beneficial to improve the reducing power of the sclerotium extract of Q1 strain.

3.7. Effect of Selenium on DPPH Radical Scavenging Ability of Q1 Strain. Table 5 showed the effect of selenium-enriched culture conditions on DPPH free radical scavenging ability of sclerotia of Penicillium thomii Q1.

In the MEA medium, the $\mathrm{EC}_{50}$ value of $\mathrm{DPPH}$ free radical scavenging ability of the sclerotium extract of Q1 strain had a negative correlation with the concentration of exogenous $\mathrm{Na}_{2} \mathrm{SeO}_{3}(R=-0.230)$, and the DPPH free radical scavenging ability of the control was the largest $(0.41 \mathrm{mg} / \mathrm{mL})$. Under different culture conditions, the DPPH free radical scavenging ability was $\mathrm{MEA}+\mathrm{Na}_{2} \mathrm{SeO}_{3} 10 \mu \mathrm{g} / \mathrm{mL}>\mathrm{MEA}+\mathrm{Na}_{2} \mathrm{SeO}_{3}$ $3 \mu \mathrm{g} / \mathrm{mL}>\mathrm{MEA}+\mathrm{Na}_{2} \mathrm{SeO}_{3} 6 \mu \mathrm{g} / \mathrm{mL}$.

In the MEA medium, there was a positive correlation between $\mathrm{EC}_{50}$ value of DPPH free radical scavenging ability and SeMet concentration $(R=0.241)$. The DPPH free radical scavenging ability of the control was the largest $(0.47 \mathrm{mg} / \mathrm{mL})$. The scavenging ability of DPPH free radical in different culture conditions was MEA+SeMet $20 \mu \mathrm{g} / \mathrm{mL}>\mathrm{MEA}+$ SeMet $5 \mu \mathrm{g} / \mathrm{mL}>\mathrm{MEA}+$ SeMet $10 \mu \mathrm{g} / \mathrm{mL}$.

These results showed that the addition of SeMet was not conducive to the improvement of DPPH free radical scavenging ability by Q1 strain, and the addition of $\mathrm{Na}_{2} \mathrm{SeO}_{3}$ $(10 \mu \mathrm{g} / \mathrm{mL})$ with higher concentration was conducive to the improvement of DPPH free radical scavenging ability of Q1 strain, but the degree of improvement was not significant.

3.8. Effect of Selenium on the Chelating Ability of Ferrous Ions in the Sclerotia of Q1 Strain. Table 6 showed the effect of selenium-enriched culture conditions on the chelating ability of ferrous ions in the sclerotia of Penicillium thomii Q1.

It can be seen from Table 6 that in the MEA medium, there is a significant positive correlation $(R=0.954)$ between $\mathrm{EC}_{50}$ value of ferrous ion chelating ability of sclerotium extract of Q1 strain and the concentration of exogenous $\mathrm{Na}_{2} \mathrm{SeO}_{3}$. The ferrous ion chelating ability of the control is the largest $(0.41 \mathrm{mg} / \mathrm{mL})$. Under different culture conditions, the ferrous ion chelating ability was MEA

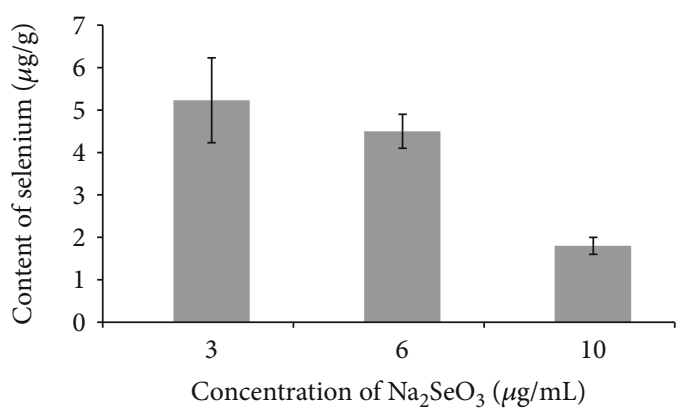

FIgURE 5: Effect of $\mathrm{Na}_{2} \mathrm{SeO}_{3}$ on selenium content in sclerotia of Q1 strain.

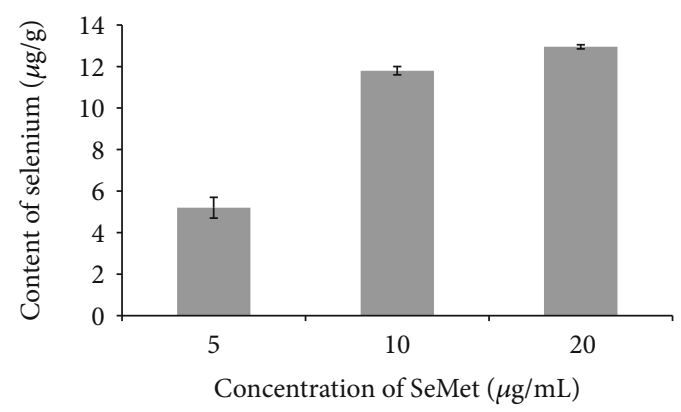

Figure 6: Effect of SeMet on selenium content in sclerotia of Q1 strain.

$+\mathrm{Na}_{2} \mathrm{SeO}_{3} 3 \mu \mathrm{g} / \mathrm{mL}>\mathrm{MEA}+\mathrm{Na}_{2} \mathrm{SeO}_{3} 6 \mu \mathrm{g} / \mathrm{mL}>\mathrm{MEA}+\mathrm{Na}_{2} \mathrm{SeO}_{3}$ $10 \mu \mathrm{g} / \mathrm{mL}$.

In the MEA medium, $\mathrm{EC}_{50}$ value of ferrous ion chelating ability of the extract of Q1 strain was positively correlated with SeMet concentration $(R=0.981)$, and the ferrous ion chelating ability of the control was the largest $(0.41 \mathrm{mg} / \mathrm{mL})$. Under different culture conditions, the ferrous ion chelating ability was $\mathrm{MEA}+$ SeMet $5 \mu \mathrm{g} / \mathrm{mL}>$ MEA+SeMet $10 \mu \mathrm{g} / \mathrm{mL}>$ MEA + SeMet $20 \mu \mathrm{g} / \mathrm{mL}$.

The results showed that the addition of $\mathrm{Na}_{2} \mathrm{SeO}_{3}$ and SeMet was not conducive to the improvement of ferrous chelation ability by Q1 strain.

3.9. Effect of Selenium on Selenium Content of Sclerotia of Q1 Strain. Figure 5 showed the effect of different concentration of $\mathrm{Na}_{2} \mathrm{SeO}_{3}$ added to the culture medium on selenium content in sclerotia of Penicillium thomii Q1.

It can be seen from Figure 5 that there was a weak positive correlation $(R=0.128)$ between the selenium content of the sclerotia of Q1 strain and the concentration of exogenous $\mathrm{Na}_{2} \mathrm{SeO}_{3}$ at the MEA medium, and it reached the maximum $(5.23 \mu \mathrm{g} / \mathrm{g})$ when the concentration of $\mathrm{Na}_{2} \mathrm{SeO}_{3}$ was $3 \mu \mathrm{g} / \mathrm{mL}$.

Figure 6 showed the effect of adding SeMet of different concentrations to the culture medium on the selenium content in the sclerotia of Penicillium thomii Q1.

It can be seen from Figure 6 that there was a significant positive correlation $(R=0.920)$ between the selenium content in the sclerotia of Q1 strain and the concentration of SeMet in the exogenous medium, and it reached the 
maximum $(12.95 \mu \mathrm{g} / \mathrm{g})$ when the SeMet concentration is $20 \mu \mathrm{g} / \mathrm{mL}$.

The results showed that lower concentration of $\mathrm{Na}_{2} \mathrm{SeO}_{3}$ $(3 \mu \mathrm{g} / \mathrm{mL})$ and higher concentration of SeMet $(20 \mu \mathrm{g} / \mathrm{mL})$ in the MEA medium were beneficial to the increase of Se content in sclerotia of Q1 strain.

\section{Discussion}

$\mathrm{Na}_{2} \mathrm{SeO}_{3}$ is the most commonly used selenium-enriching agent [25], which is mainly used in the study of animals [26] and plants [27] and fungi [28] and large edible fungi [29]. However, $\mathrm{Na}_{2} \mathrm{SeO}_{3}$ is toxic, which limits its use. SeMet, as an organic selenium, is less toxic than $\mathrm{Na}_{2} \mathrm{SeO}_{3}$. However, the research of SeMet is not as extensive as that of $\mathrm{Na}_{2} \mathrm{SeO}_{3}$. At present, SeMet is mainly used as a selenium-enriching agent in animals [30] and plants [31], and its effect on yeast and large edible fungi in fungi has not been seen. In recent years, we have studied the effect of SeMet on the cultivation of Pleurotus flavus [32]. However, the selenium-enriched culture of Sclerotinia (mainly Micrococcus) fungi on $\mathrm{Na}_{2} \mathrm{SeO}_{3}$ and SeMet has not been reported.

Our previous experiments $[13,14]$ had shown that when the PT95 strain was grown under high oxidative stress condition, its sclerotial biomass was higher than that at low oxidative stress condition. Our experiments showed that the carotenoid, ascorbic acid, phenolic compounds, and selenium could be accumulated in the sclerotia of Q1 strain by adding different concentrations of inorganic and organic selenium in the MEA medium, and the content of carotenoid, ascorbic acid, and selenium in the sclerotia of Q1 strain could be increased to different degrees, but the content of total phenol could not be increased. Therefore, adding a certain concentration of selenium is beneficial to the increase of carotenoid and ascorbic acid content in sclerotia, but not to the increase of total phenolic content. So, we think that selenium may have some synergistic effect with carotenoids and ascorbic acid. These results indicated that ROS may induce antioxidant defense of Q1 strain by producing carotenoids instead of phenolic compounds in concentration levels related to the degree of oxidative stress. Mei et al. found that the structure of the fungal community was related to selenium content [33].

Selenium was found in Cordyceps militaris, Penicillium expansum, Ganoderma lucidum, Saccharomyces cerevisiae, etc. influencing the growth of fungi [33-36]. And selenium also affects antioxidant activity.

The antioxidant potential of the sclerotia could be attributed to its various characteristics. DPPH free radical scavenging activity and the reducing capacity of a compound may serve as a significant indicator of its potential antioxidant activity. In addition, when the concentration of $\mathrm{Na}_{2} \mathrm{SeO}_{3}$ and SeMet in the medium was $10 \mu \mathrm{g} / \mathrm{mL}$, the reducing power of Q1 sclerotium extract was improved. Except that the concentration of $\mathrm{Na}_{2} \mathrm{SeO}_{3}$ was $10 \mu \mathrm{g} / \mathrm{mL}$, the DPPH free radical scavenging ability of the extract from the sclerotia of strain Q1 could not be improved. Adding different concentrations of inorganic and organic selenium is not conducive to the improvement of the chelating ability of ferrous ions in Q1 sclerotium extract. Therefore, we think that the addition of selenium may change the proportion of various antioxidants in the antioxidant system, so that there are differences among the indicators.

\section{Conclusions}

Inorganic selenium and organic selenium were effectively added to the culture medium. Selenium could affect the differentiation and antioxidant activity of Q1 strain. The experimental results can provide a new research idea for the utilization and development of Penicillium sclerotium and selenium.

\section{Data Availability}

The data used to support the findings of this study are available from the corresponding author upon request.

\section{Conflicts of Interest}

None of the authors has any other conflicts of interest related to this paper.

\section{Authors' Contributions}

Wenjing Zhao designed and conducted the experiments, analyzed the data, and wrote the manuscript. Feihong Zhai conducted the experiments. Jianrong Han provided technical support. All authors read and approved the final manuscript.

\section{Acknowledgments}

The project is supported by the Shanxi Province Youth Fund Project (201701D221165), Scientific and Technologial Innovation Programs of Higher Education Institutions in Shanxi (2019L0780), the talent start-up fund of Taiyuan Normal University.

\section{References}

[1] G. N. Agrios, Plant Pathology, Academic Press, New York, NY, USA, 1988.

[2] I. Chet and Y. Henis, "Sclerotial morphogenesis in fungi," Annual Review of Phytopathology, vol. 13, no. 1, pp. 169-192, 1975.

[3] J. R. Coley-Smith and R. C. Cooke, "Survival and germination of fungal sclerotia," Annual Review of Phytopathology, vol. 9, no. 1, pp. 65-92, 1971.

[4] H. J. Willetts, "The survival of fungal sclerotia under adverse environmental conditions," Biological Reviews, vol. 46, no. 3, pp. 387-407, 1971.

[5] C. D. Georgiou, "Lipid peroxidation in Sclerotium rolfsii: a new look into the mechanism of sclerotial biogenesis in fungi," Mycological Research, vol. 101, no. 4, pp. 460-464, 1997.

[6] B. Halliwell, "Reactive species and antioxidants. Redox biology is a fundamental theme of aerobic life," Plant Physiology, vol. 141, no. 2, pp. 312-322, 2006.

[7] J. C. Espín, M. T. García-Conesa, and F. A. Tomás-Barberán, "Nutraceuticals: facts and fiction," Phytochemistry, vol. 68, no. 22-24, pp. 2986-3008, 2007. 
[8] A. Winata and K. Lorenz, "Antioxidant potential of 5-n-pentadecylresorcinol," Journal of Food Processing \& Preservation, vol. 20, no. 5, pp. 417-429, 1996.

[9] K. Kiritsakis, M. G. Kontominas, C. Kontogiorgis, D. Hadjipavlou-Litina, A. Moustakas, and A. Kiritsakis, "Composition and antioxidant activity of olive leaf extracts from Greek olive cultivars," Journal of the American Oil Chemists' Society, vol. 87, no. 4, pp. 369-376, 2010.

[10] X. B. Zhang, Biological Efficacy of Se-Enriched Ligustrum lucidum Fruit, Yangzhou University, 2012.

[11] Y. Lu, W. F. Huang, and H. C. Yang, "The biological function of selenium," Hubei Journal of Animal and Veterinary Sciences, vol. 1, pp. 7-9, 2012.

[12] J. R. Han, Z. W. Li, Y. Wang, Q. Wang, and Q. Wang, "Biological characteristics of one Penicillium strain producing sclerotia," Journal of Shanxi University, vol. 32, pp. 634-639, 2009.

[13] J. R. Han, W. J. Zhao, Y. Y. Gao, and J. M. Yuan, "Effect of oxidative stress and exogenous $\beta$-carotene on sclerotial differentiation and carotenoid yield of Penicillium sp. PT95," Letters in Applied Microbiology, vol. 40, no. 6, pp. 412-417, 2005.

[14] X. L. Li, X. H. Cui, and J. R. Han, "Sclerotial biomass and carotenoid yield of Penicillium sp. PT95 under oxidative growth conditions and in the presence of antioxidant ascorbic acid," Journal of Applied Microbiology, vol. 101, no. 3, pp. 725-731, 2006.

[15] W. J. Zhao, Study on the Cell Response of Penicillium Thomii PT95 and Q1 Strains to Oxidative Stress, Shanxi University, 2014.

[16] C. D. Georgiou, N. Tairis, and A. Polycratis, "Production of $\beta$-carotene by Sclerotinia sclerotiorum and its role in sclerotium differentiation," Mycological Research, vol. 105, no. 9, pp. 1110-1115, 2001.

[17] C. D. Georgiou, N. Patsoukis, I. Papapostolou, and G. Zervoudakis, "Sclerotial metamorphosis in filamentous fungi is induced by oxidative stress," Integrative and Comparative Biology, vol. 46, no. 6, pp. 691-712, 2006.

[18] S. McDonald, P. D. Prenzler, M. Autolovich, and K. Robards, "Phenolic content and antioxidant activity of olive extracts," Food Chemistry, vol. 73, no. 1, pp. 73-84, 2001.

[19] T. Kuda, M. Tsunekawa, H. Goto, and Y. Araki, “Antioxidant properties of four edible algae harvested in the Noto Peninsula, Japan," Journal of Food Composition and Analysis, vol. 18, no. 7, pp. 625-633, 2005.

[20] K. Shimada, K. Fujikawa, K. Yahara, and T. Nakamura, “Antioxidative properties of xanthan on the autoxidation of soybean oil in cyclodextrin emulsion," Journal of Agricultural and Food Chemistry, vol. 40, no. 6, pp. 945-948, 1992.

[21] O. Talaz, İ. Gülçin, S. Göksu, and N. Saracoglu, “Antioxidant activity of 5,10-dihydroindeno[1,2-b]indoles containing substituents on dihydroindeno part," Bioorganic \& Medicinal Chemistry, vol. 17, no. 18, pp. 6583-6589, 2009.

[22] Q. Y. Chen, Y. J. Sun, and F. Yin, "Determination of Se and polysaccharide in selenium enriched Ganoderma lucidum," Forest By-Product and Speciality in China, vol. 2, pp. 16-18, 2010.

[23] H. Chen, D. Y. Sun, and L. F. Zhang, "Optimization of the medium of Se-enriched Ganoderma lucidum," Science and Technology of Food Industry, vol. 4, pp. 110-112, 2008.

[24] A. A. Ray, SAS Users Guide: Statistics, SAS Institute, Cary, NC, USA, 1985.
[25] W. P. Mu, Y. Tian, J. H. Piao, L. Gu, and X. Yang, "Studies on comparing the toxicity between sodium selenite and selenomethionine in rats," Journal of Hygiene Research, vol. 33, no. 6, pp. 700-703, 2004.

[26] J. Li, L. Zuo, T. Shen, and Z. N. Zhang, "Sodium seleniteinduced oxidative stress and apoptosis in human acute promyelocytic leukemia NB4 cells," Acta Pharmaceutica Sinica, vol. 37, no. 9, pp. 677-681, 2002.

[27] S. L. Liu, C. Ma, X. L. Jie et al., "Effect of sodium selenite application by leaf surfaces praying on the yield and quality of alfalfa," Pratacultural Science, vol. 25, no. 8, pp. 73-78, 2008.

[28] B. Yang, Preparation and Properties of Selenium Enriched Candida Prion, Suzhou University, 2012.

[29] H. W. Li, M. Tie, W. Zhang, Y. Zhang, and D. Zhao, "Se-enriched characteristics of the mushroom Flammulina velutipes," Mycosystema, vol. 31, no. 1, pp. 86-91, 2012.

[30] Z. Y. Jiang, Y. Wang, Y. C. Lin, C. Zheng, S. Jiang, and F. Chen, "Effects of dietary selenomethionine supplementation on performance and meat quality of finishing pigs," Chinese Journal of Animal Nutrition, vol. 22, no. 2, pp. 293-300, 2010.

[31] L. X. Wang and J. H. Tang, "Effects of selenium on nutrient accumulation and nutrition quality of Brassica juncea," Guizhou Agricultural Sciences, vol. 39, no. 12, pp. 75-79, 2011.

[32] L. R. Niu, Z. Q. Zhang, D. D. Long, Y. Liu, and J. R. Han, “A preliminary study on the cultivation of Pleurotus geesteranus in medium containing organic selenium," Journal of Shanxi Agricultural Sciences, vol. 41, no. 10, article 1076, 2013.

[33] Y. J. Mei, J. Q. Xiang, J. W. Zhen, and S. Wang, "Primary investigation of the fungal diversity in selenium -rich ore," Biotechnology, vol. 27, no. 1, pp. 53-57, 2017.

[34] Z. L. Wu, X. B. Yin, Z. Q. Lin et al., "Inhibitory effect of 1selenium against Penicillium expansum and its possible mechanisms of action," Current Microbiology, vol. 69, no. 2, pp. 192-201, 2014.

[35] M. Y. Ma, X. F. Zhang, Z. H. Ma, and Z. W. Jiao, "Effect of sodium selenite $\left(\mathrm{Na}_{2} \mathrm{SeO}_{3}\right)$ on fruiting body growth, adenosine and cordycepin of functional components in medical edible fungus of Cordyceps militaris," Xinjiang Agricultural Sciences, vol. 39, no. 2, pp. 1510-1517, 2019.

[36] M. Yoshinaga, S. How, D. Blanco et al., "Directed evolution of Saccharomyces cerevisiae for increased selenium accumulation," Microorganisms, vol. 6, no. 3, pp. 81-95, 2018. 